\title{
Analisis Kegagalan Baut Exhausted Lokomotif Mesin Diesel Elektrik Ditinjau Dari Struktur Mikro Material Dan Distribusi Tegangan Oleh Momen Puntir
}

\author{
Abduh Bayu Adriathma1, Ojo Kurdi ${ }^{1,2, *}$, Djoeli Satrijo ${ }^{1}$, Agus Suprihanto ${ }^{1}$ \\ ${ }^{1}$ Departemen Teknik Mesin, Universitas Diponegoro, \\ J1. Prof Soedarto, SH., Kec. Tembalang, Kota Semarang, Jawa Tengah \\ ${ }^{2}$ National Center for Sustainable Transportation Technology, Indonesia \\ *E-mail: ojokurdi@ft.undip.ac.id
}

Diterima: 11-07-2021; Direvisi: 27-11-2021; Dipublikasi: 30-12-2021

\begin{abstract}
Abstrak
Lokomotif merupakan bagian dari kereta api dimana terdapat mesin untuk menggerakkan kereta api. Salah satu jenis dari kereta api di Indonesia yaitu menggunakan mesin diesel. Pada mesin diesel terdapat exhaust yang berfungsi sebagai saluran pembuangan gas emisi. Perawatan lokomotif memungkinkan terjadinya patah pada baut exhaust. Penelitian ini bertujuan untuk mengetahui penyebab kegagalan dari baut yang dipakai pada exhaust lokomotif diesel dengan meninjau perubahan struktur mikroskopik yang terjadi pada baut dengan kondisi temperature tinggi dan mengetahui distribusi tegangan yang terjadi pada baut pada saat pelepasan. Kondisi pada daerah exhaust lokomotif kereta api dapat mencapai diatas $750^{\circ} \mathrm{C}$ menyebabkan perubahan struktur kristal dari material pada baut. Modulus kegagalan punter lebih rawan terjadi pada material ulet. Material baut SAE grade 5 ukuran 1 inch memiliki nilai torsi maksimum material 885,8 N.m dengan nilai standardnya yaitu 664 N.m. Dengan demikian menunjukkan bahwa pada saat temperature ruang torsi yang diberikan pada saat pelepasan baut memiliki nilai yang aman, namun dengan meningkatnya temperature menurunkan nilai tegangan maksimum material baut untuk terdeformasi puntir.
\end{abstract}

Kata kunci: Baut Exhausted; Struktur Mikro; Tegangan

\begin{abstract}
Locomotive is main part of train where there is an engine to move the train. One type of train in Indonesia is using a diesel engine, that there is an exhaust system for the functions as a gas emission channel. Locomotive maintenance allows for broken exhaust bolts. This study aims to determine the cause of the failure of the bolts used in the diesel locomotive exhaust by reviewing the microscopic structural changes that occur in the bolts with high temperature conditions and knowing the stress distribution that occurs in the bolts at this time. The conditions in the exhaust area of train locomotives can reach above $750^{\circ} \mathrm{C}$ changes the crystal structure of the material on the bolt. Torsional failure is more prone to occur in ductile materials. Then the 1 inch SAE grade 5 bolt material has a maximum torque value of 885.8 N.m with the standard value of 664 N.m. Thus, it shows that at room temperature the torque applied at the time of bolt removal has a safe value, but with increasing temperature, the maximum stress value of the bolt material is reduced for torsional deformation.
\end{abstract}

Keywords: Bolt Exhausted; Microstructure; Stress

\section{Pendahuluan}

Lokomotif merupakan bagian dari kereta api dimana terdapat mesin untuk menggerakkan kereta api [1]. Salah satu jenis dari kereta api di Indonesia yaitu menggunakan mesin diesel sebagai sumber tenaga yang kemudian menggerakkan roda kereta api. Dalam mesin diesel terdapat komponen-komponen yang saling terhubung dan pada bagian mesin diesel terdapat daerah exhaust yang berfungsi sebagai saluran pembuangan gas emisi [2-4].

Komponen exhaust terdiri dari beberapa bagian yang mengharuskan untuk terdapat sambungan [5]. Daerah exhaust memiliki kondisi temperatur yang sangat tinggi sehingga ketahanan material terhadap temperatur sangat penting karena dapat mempengaruhi sifat dan kondisi dari material tersebut. Perawatan lokomotif memungkinkan untuk melakukan pelepasan pada bagian bagian exhaust, dengan mengetahui prosedur serta kondisi baik yang tampak maupun secara mikro merupakan keharusan sehingga tidak terjadi kegagalan atau dalam hal ini yaitu terjadinya patah pada baut exhaust. 
Abduh Bayu Adriathma dkk /Jurnal Rekayasa Mesin

p-ISSN: 1411-6863, e-ISSN: 2540-7678

Vol.16|No.3|353-358|Desember|2021

Permasalahan terjadi ketika terjadi patah pada baut daerah exhaust, dengan letak dan posisi exhaust lokomotif yang susah dijangkau menyebabkan saat terjadi patah pada baut akan membutuhkan waktu yang cukup lama untuk melepaskan patahan tersebut meskipun telah menggunakan alat bantu. Hal inilah yang menjadi dasar dilakukan penelitian penyebab kegagalan atau terjadinya patah pada baut exhaust agar dapat menghidarinya.

Penelitian dimulai dengan melakukan studi lapangan dan mengidentifikasi masalah, kemudian dilanjutkan dengan mencari dan mempelajari literatur yang berkaitan serta mengambil data untuk kemudian dianalisis dan disimpulkan sehingga diperoleh pembahasan seacar teoritis yang valid. Dengan tujuan untuk mengetahui penyebab kegagalan dari baut yang dipakai pada exhaust lokomotif diesel dengan meninjau perubahan struktur mikroskopik yang terjadi pada baut dengan kondisi temperatur tinggi dan mengetahui distribusi tegangan yang terjadi pada baut pada saat pelepasan. Batasan yang diberikan yaitu baut yang digunakan yaitu baut ukuran 1 inch, material karbon medium SAE grade 5. Perihal penyebab kegagalan lain yaitu akibat korosi, koefisien gesek, serta pelumas yang terjadi pada permukaan baut diabaikan.

\section{Material dan metodologi}

\subsection{Material}

Material Baut pada exhaust lokomotif diesel menggunakan SAE Grade 5 dengan bahan medium carbonsteel, ukuran yang digunakan yaitu 1 inch dengan head height 0.546 inch, 8 threads per inch. Baut 1 Inch SAE Grade 5 memiliki nilai standard torsi 440-490 Lb.Ft atau bernilai 597-664 N.m. Baut exhaust ditunjukkan pada Gambar 1.

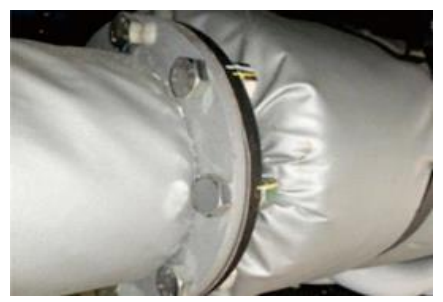

Gambar 1. Baut pada Exhausted

\subsection{Metodologi}

Proses penelitian memperoleh penyelesaian dalam bentuk diagram alir penelitian ditunjukkan pada Gambar 2 . Dimulai dengan melakukan tinjauan ke lokasi kereta api untuk melihat langsung lokasi dan keadaan sehingga dapat mendefinisikan permasalahan tersebut, kemudian merumuskan masalah yang terjadi pada baut dengan beberapa hipotesis pada penelitian dan studi terdahulu, kemudian mencari data penunjang agar dapat dilakukan analisis terjadinya deformasi baut. Pada penelitian ini beberapa analisis yang dilakukan yaitu analisis struktur mikro material dan analisis pembebana dengan melihat nilai distribusinya. Hasil dari analisis yang didapatkan kemudian disimpulkan untuk dapat memeberikan rekomendasi agar kegagalan tidak terjadi kembali dengan permasalahan yang sama di waktu yang akan datang.

Dalam melakukan perhitungan pada saat analisis pembebananan, beberapa persamaan dipakai dalam perhitungan analasisi, untuk menghitung proof load untuk menentukan kekuatan tegangan pada material baut ditunjukkan pada Persamaan 1 berikut.

$\mathrm{Pm}=$ St $\times$ As $\times \frac{100}{75}$

Kemudian dilanjutkan mencari torsi pada proof load tersebut, ditunjukkan pada Persamaan 2.

$\mathrm{T}=\mathrm{K} \times \mathrm{D} \times \mathrm{Pm}$

Untuk mendapatkan nilai tegangan yang diterima suatu titik pada baut dan nilai maksimum yang dapat diterima diperoleh dengan perhitungan pada Persamaan 3. 
$\tau r_{1}=\frac{\text { T.r1 }}{\mathrm{J}(\text { pejal })}$

Dan untuk memperoleh nilai sudut puntir yang dihasilkan menggunakan Persamaan 4.

$\varphi=\frac{\mathrm{TL}}{\mathrm{JG}}$

Sedangkan nilai regangan yang dihasilkan pada saat terjadi puntiran oleh beban torsi ditunjukkan pada Persamaan 5.

$\gamma \max =\frac{r \cdot \varphi}{\mathrm{L}}$

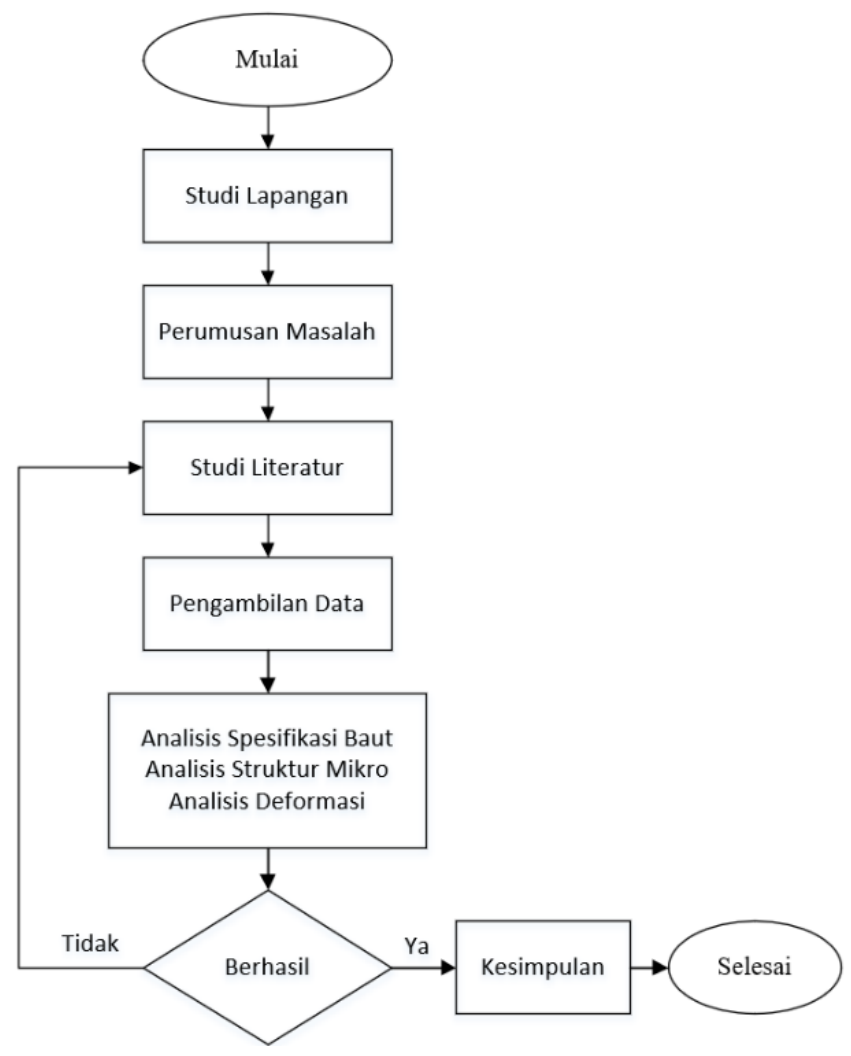

Gambar 2. Diagram Alir Penelitian

\section{Hasil dan pembahasan}

\subsection{Identifikasi struktur mikro}

Baut yang diteliti merupakan baut jenis SAE J429, materialnya yaitu medium karbon dengan kandungan karbon 0.3 - $0.6 \%$ wt. Kemudian kondisi pada daerah exhaust lokomotif kereta api dapat mencapai diatas $750 \mathrm{C}$ yang mana hal tersebut secara memberikan perlakuan panas sehingga dapat menyebabkan perubahan struktur kristal dari material pada baut [5]. Untuk mengidentifikasi struktur kristal yang terbentuk, dapat ditentukan dengan mengetahui fase dari struktur mikro material dengan menggunakan diagram fasa Fe-Fe3C [6] ditunjukkan pada Gambar 3.

Pada gambar diagram $\mathrm{Fe}-\mathrm{Fe} 3 \mathrm{C}$ menunjukkan bahwa material terjadi pada fase pearlite, yang mana pada fase pearlite seluruh komposisi memiliki struktur kristal BCC [6,7], kemudian saat terjadi kenaikan temperatur hingga menyentuh $750^{\circ} \mathrm{C}$, sebagian komposisi berubah menjadi struktur FCC karena berada pada fase $\alpha+\gamma$ karena struktur yang terjadi pada fase austenite merupakan struktur kristal FCC. Selain itu jika menyentuh temperatur $750^{\circ} \mathrm{C}$ ada kemungkinan material medium carbon pada sebagian komposisinya terjadi heat treatment yang bersifat softening [8]. Struktur FCC dengan jumlah atom yang lebih banyak dibandingkan dengan BCC berdampak pada material yaitu bersifat ulet atau dapat dikatakan struktur BCC berdampak sifat getas [9]. Struktur kristal dapat dilihat pada Gambar 4. 


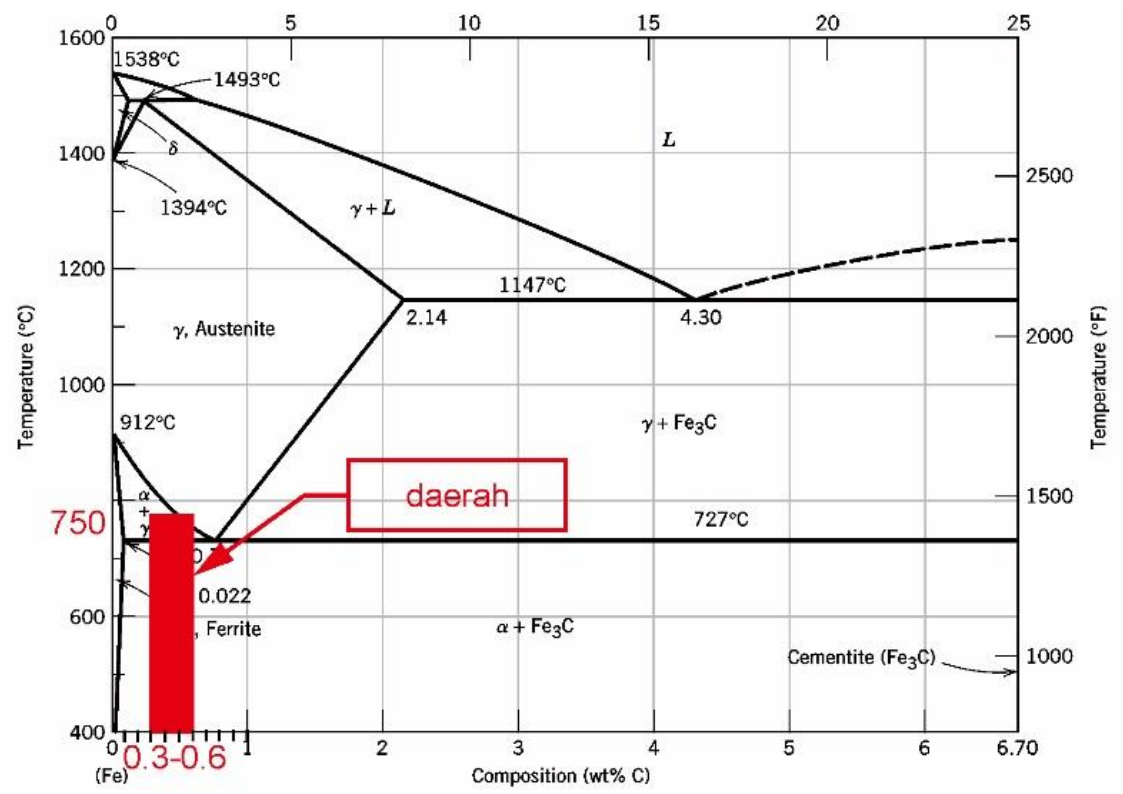

Gambar 3. Diagram Fase Fe-Fe3C

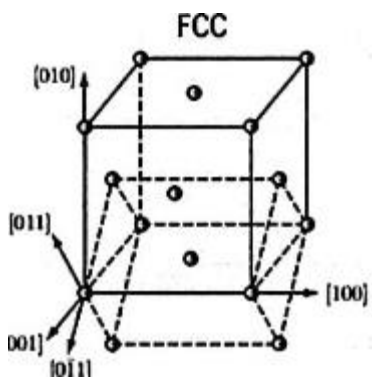

BCC

Gambar 4. Struktur Kristal FCC dan BCC

Modus kegagalan material yaitu sifat keuletan lebih mudah gagal pada tegangan geser sedangkan sifat getas lebih mudah gagal pada tegangan tarik. Hal ini dikarenakan spesimen ulet gagal pada tegangan geser maksimum yang terjadi pada bidang yang tegak lurus terhadap sumbu poros, dan pembebanan pada spesimen getas terjadi sepanjang bidang yang tegak lurus terhadap tegangan tarik maksimum yaitu sepanjang permukaan $55^{\circ} \mathrm{C}$ terhadap sumbu poros [10-13].

Selain itu material yang masih dalam keadaan temperatur tinggi dapat dikatakan lebih tidak stabil dibandingkan material yang berada pada temperatur ruang, hal ini dikarenakan atom pada suartu material akan selalu bergerak dan menyusun untuk mengupayakan kestabilannya dan pada saat temepeartur masih selalu berubah karena terjadi penurunan terus menerus kestabilan tersebut akan semakin jauh meskipun pada temperatur ruang pun kestabilan masih belum terjadi [14,15]. Namun demikian dikarenakan gerakan partikel partikel yang semakin cepat akibat kestabilan yang rendah menyebabkan ikatan antar molekul atom tersebut masih akan terus berubah, hal inilah yang menyebabkan mudah terdeformasi.

\subsection{Identifikasi distribusi tegangan}

Pembebanan maksimum material dapat diukur dengan menentukan kekuatan tegangan pada material baut dengan mencari nilai proof load pada baut 1 Inch SAE Grade 5 Medium Carbon Steel, dan diperoleh proof load bernilai 98.019,2 lb dengan nilai torsi yang diperbolehkan yaitu 885,8 N.m 
Abduh Bayu Adriathma dkk /Jurnal Rekayasa Mesin

p-ISSN: 1411-6863, e-ISSN: 2540-7678

Vol.16|No.3|353-358|Desember|2021

Pembebanan torsi pada material ditunjukkan pada Gambar 5 (a). Bagian-bagian baut yang diberi titik merah merupakan daerah yang menerima tegangan geser maksimum yaitu pada diameter terluar pada bagian kepala baut dengan jari jari yaitu 19,05 mm dan bagian terluar dari badan baut yang mana pada penelitian ini untuk bagian ulir diabaikan dan diameter terluar badan baut menggunakan diameter minor yaitu dengan jari jari 12,7 mm. Torsi yang diberikan berdasarkan buku Manual Instruction yaitu 664 N.m kepada baut 1 Inch SAE Grade 5 Medium CarbonSteel. Sedangkan torsi maksimum yang mampu diterima adalah 885.8 N.m dengan factor of safetynya yaitu 1,33. Distribusi Tegangan yang terjadi ditunjukkan pada Gambar 5(b).

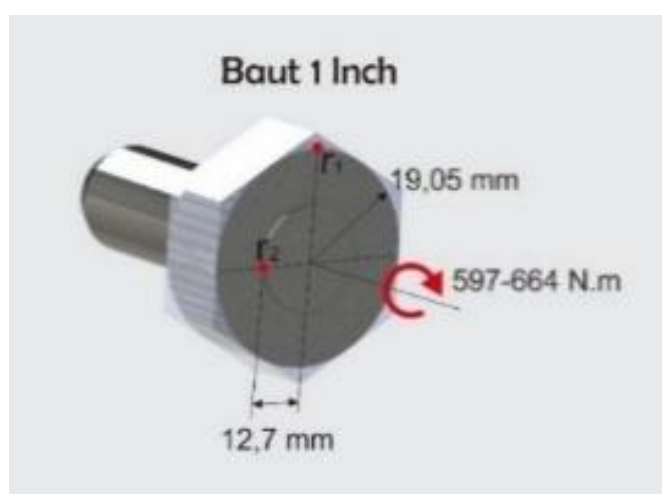

(a)

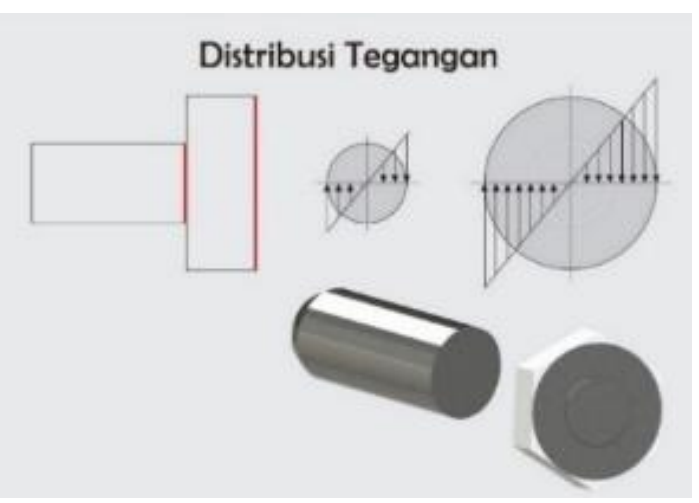

(b)

Gambar 5. (a) Keadaan Baut Saat Diberikan Pembebanan dan (b) Distribusi Tegangan pada Baut

Nilai pada masing masing daerah pada baut memiliki nilai tegangannya masing-masing dengan nilai maksimum yaitu berada pada sepanjang diameter titik merah melingkar yang ditunjukkan pada gambar 5.7 karena merupakan jari jari terluar baik pada kepala baut maupun badan baut.

Tegangan pada titik $\boldsymbol{r}_{\mathbf{1}}$ merupakan nilai maksimum yang diterima oleh kepala baut pada saat pemberian torsi 664 N.m, yaitu pembebanan tertinggi berdasarkan buku manual instruction. Nilai dari tegangan $\boldsymbol{r}_{\mathbf{1}}$ yaitu $61,12 \mathrm{Mpa}$, sedangkan nilai tegangan yang dapat diterima oleh baut pada tititk $\boldsymbol{r}_{\mathbf{1}}$ yaitu 83,46 Mpa. Kemudian tegangan pada titik $\boldsymbol{r}_{\mathbf{2}}$ merupakan nilai maksimum yang diterima oleh badan baut. Nilai dari tegangan pada titik $\boldsymbol{r}_{\mathbf{2}}$ yaitu 40,75 Mpa sedangkan nilai tegangan yang dapat diterima oleh baut pada titik $\boldsymbol{r}_{2}$ yaitu 54,35 Mpa. Hal ini menunjukkan bahwa tegangan yang terjadi pada baut pada saat pelepasan masih menunjukkan kesesuaian nilai yang masih dapat diterima.

Selanjutnya,saat diberikan momen puntir, material pada baut akan mengalami deformasi yang menghasilkan regangan geser dan juga sudut puntiran.Terjadinya deformasi akibat beban puntir akan menghasilkan sudut puntir 0,000620432 rad, sedangkan nilai sudut puntir maksimum yang dapat diterima sebelum terjadinya deformasi plastis yaitu $0,000826931 \mathrm{rad}$. Dan nilai regangan puntir maksimum yang terjadi pada badan baut yaitu 0,00050934 mm sedangkan nilai regangan puntir maksimum yang dapat diterima sebelum terjadinya deformasi plastis yaitu $0,000678864 \mathrm{~mm}$. Dengan nilai tersebut juga menunjukkan bahwa nilai dari pemberian torsi bukanlah sebuah kesalahan yang menyebabkan kegagalan pada baut tersebut.

\section{Kesimpulan}

Berdasarkan analisis yang telah dilakukan, kegagalan yang terjadi pada baut diakibatkan oleh beberapa faktor, antara lain yaitu pengaruh mikro struktur material, pemberian gaya torsi yang mengakibatkan tegangan berlebih, dan juga faktor lainnya. Identifikasi berdasarkan struktur mikro material baut material medium carbon grade 5 , kondisi temperatur $750^{\circ} \mathrm{C}$ 
Abduh Bayu Adriathma dkk /Jurnal Rekayasa Mesin p-ISSN: 1411-6863, e-ISSN: 2540-7678 Vol.16|No.3|353-358|Desember|2021

mengubah struktur kristal BCC menjadi FCC karena fase perlite berubah menjadi perlit + austenite bahkan mempengaruhi heat treatment softening, dan dikarenakan fase FCC ber ulet sehingga menyebabkan material baut keuletannya menjadi meningkat sedangkan kegagalan puntir itu sangat dipengaruhi oleh keuletan yang tinggi dibandingan kegetasan yang tinggi. Kestabilan atom saat terjadi panas juga mempengaruhi patah yang terjadi karena ikatannya yang belum stabil. Kemudian distribusi tegangan yang terjadi akibat momen puntir atau torsi yang diberikan saat sedang melakukan pelepasan baut dengan torsi 156 N.m yaitu bervariasi linear dari titik tengah penampang dengan tegangan geser tertinggi berada pada jari-jari terluar bagian kapala baut dan badan baut, yang nilainya yaitu 7,3545 Mpa pada tegangan maksimum kepala baut, dan 3,2955 Mpa pada tegangan maksimun badan baut. Deformasi yang terjadi akibat beban puntir yaitu menghasilkan sudut puntir 0,000038 radian dan menghasilkan regangan puntir maksimum pada badan baut sebesar $0.0000498 \mathrm{~mm}$

\section{Daftar Pustaka}

1. Safriansyah B. Lokomotif sebagai Sumber Ide Pembuatan Karya Kriya Logam. State University of Surabaya; 2017.

2. Ridwanullah R, Tirtakusumah HS. Analisis Faktor-Faktor Yang Mempengaruhi Permintaan Jasa Kereta Api Rute Sukabumi-Bogor. Perpustakaan Fakultas Ekonomi dan Bisnis Unpas; 2019.

3. Purwanto H. Sistim Transmisi Lokomotif Diesel. J Ilm Momentum. 2006;2(1).

4. Harjanto S. Simulasi Pengereman Emergency Pada Kereta Api Melewati Sinyal Berindikasi Berhenti Berbasis Mikrokontroler Arduino Uno. J Tekno. 2018;15(2):43-52.

5. Rahardjo A, Hakim ME, Wahab A. Analisa Sistem Pembakaran Pada Mesin Diesel Lokomotif CC 201. J Tek Mesin. 2017;3(02).

6. Callister WD. Fundamentals of materials science and engineering. Vol. 471660817. Wiley London; 2000.

7. Karuniawan I. Perbedaan nilai kekerasan pada proses double hardening dengan media pendingin air dan oli SAE 20 pada baja karbon rendah. Universitas Negeri Semarang; 2007.

8. Bawafi M. Analisa Brittle Crack Initiation Pada Baja Kekuatan Tinggi Akibat Pengaruh Temperatur. Institut Teknologi Sepuluh Nopember; 2001.

9. Sari NH. Material teknik. Deepublish; 2018.

10. Beer FP, Johnston ER, DeWolf J, Mazurek D. Mechanics of Materials (Vol. 5). Ohio McGraw-Hill Sci. 2008;

11. Hidayat W. Klasifikasi Dan Sifat Material Teknik Serta Pengujian Material. 2019;

12. Atho'ullah AH. Pengaruh Kedalaman Takik Ulir Whitworth Terhadap Kekuatan Lelah Puntir Dinamis Pada Baja Aisi 1010. UNNES; 2019.

13. Atho'ullah AH, Yudiono H. Karakterisasi Ketahanan Lelah Takik Ulir Whitworth Akibat Pembebanan Puntir Dinamis pada Baja Karbon Rendah. J Din Vokasional Tek Mesin. 2020;5(2):154-62.

14. Kuswanto B. Perubahan Harga Tegangan Tarik Yield Material Baja Karbon Rendah Setelah Melalui Proses Pack Carburizing. Pros SNST Fak Tek. 2010;1(1).

15. Aji WS, Nugroho S. Analisis Kegagalan Baut Pengikat Gearbox Pada Lokomotif Kereta Rel Diesel Elektrik (Krde). J Tek Mesin. 2014;2(4):413-20 